Journal of Advanced Research in Fluid Mechanics and Thermal Sciences

\title{
Modeling on the Effect of Heat Exchanger Submersion on Controlling Spontaneous Combustion in A Coal Pile
}

\author{
Jeri At Thabari ${ }^{1}$, Syailendra Supit ${ }^{2}$, Wahyu Nirbito ${ }^{1}$, Yuswan Muharam $^{2}$, Yulianto Sulistyo \\ Nugroho ${ }^{1, *}$
}

Department of Mechanical Engineering, Faculty of Engineering, Universitas Indonesia, Depok, Indonesia

Department of Chemical Engineering, Faculty of Engineering, Universitas Indonesia, Depok, Indonesia

\section{ARTICLE INFO}

\section{Article history:}

Received 13 November 2020

Received in revised form 20 February 2021

Accepted 25 February 2021

Available online 16 March 2021

\section{ABSTRACT}

Spontaneous combustion of coal has been well-known as a problem faced by coa industries, especially in storing and trans-shipping processes. The negative impacts of this phenomenon have led to several hazardous incidents and degrading product quality. Several methods have been researched to minimize the impacts; one of the proposed ways is immersing heat exchangers inside the coal stockpile. An experiment was conducted to analyze the cooling effect of an immersed simple heat exchanger made of a copper coil. By varying the number of windings, the experiment showed a significant decrease in pile temperature due to the immersed heat exchanger. This work continues exploring the possibility of applying the method by observing and analyzing the simulation model. COMSOL Multiphysics was used to model the physics phenomena that occur within the coal reactor. The effect of the heat exchanger surface area was studied from the model to observe the heat propagation within the coal reactor. The vast reach of heat propagation from the heat exchanger through the coal pile on the simulation was promisingly showing that this method was useful to limit the occurrence of spontaneous fire in coal piles.
Spontaneous combustion; Coal pile; Modeling; Immersed heat exchanger

\section{Introduction}

Coal has become the primary preference as an energy source to generate electricity. The increase in demand for energy results in a higher demand for coal. To fulfill the need, consumption of lowrank coal, such as sub-bituminous and lignite, was unavoidable. Trans-shipping is still the preferred choice for transporting coal worldwide, where coal was exposed to a long barge storage time. The problem arises in this condition, especially with low-rank coal, where it leads to self-healing phenomena of the coal. This self-heating phenomenon could lead to more disastrous conditions such as coal seam fire in mining operations $[1,2]$. Researchers keep proposing methods to suppress fire in the coal pile [3]. In terms of prevention, controlling the temperature of the system ranged from using

\footnotetext{
* Corresponding author.

E-mail address: yulianto.nugroho@ui.ac.id
}

https://doi.org/10.37934/arfmts.81.1.158164 
a chemical agent to convective heat transfer manipulation in the coal pile surroundings [4-6] had also been proposed. These methods have their advantages and disadvantages in practice.

Nonetheless, researchers are faced with more complicated problems of finding a more effective way of minimizing the unwanted effects of the spontaneous combustion phenomenon. One method currently being developed to control the coal temperature is by immersing the heat exchanger in a coal pile [7-9]. Another study also found that the immersed heat exchanger will not disrupt the pile's loading capacity both in storage and trans-shipping processes [10].

This work aims to study the cooling effect of heat exchanger immersion using a mathematical model. It was done by setting the heat exchanger surface area as the variables and analyzing the heat distribution. The difference between laboratory experiment and the modeling result were also analysed. The modeling was carried out using COMSOL Multiphysics. The modeling of coal selfheating using COMSOL had been done previously to determine the characteristics of its spontaneous combustion by modeling the heat distribution of the coal when heated [11-13]. This study presents the effect of the heat exchanger surface area by varying the coil geometry. The distribution of transferred heat inside the coal pile via a non-disruptive cooling process was also investigated in this study.

\section{Methodology}

\subsection{Experimental Set-Up}

Experiments were carried out by heating the coal pile in the oven by varying the immersed heat exchanger's coil windings (Figure 1). The variables were set from two to seven windings. The coal pile was heated inside a cylindrical reactor made of stainless steel wire mesh with dimensions of $110 \mathrm{~mm}$ $x 115 \mathrm{~mm}$. Before being put into the reactor, the sample was crushed and filtered using two filtering types, with the first filter measuring $6 \mathrm{~mm} \times 6 \mathrm{~mm}$ and the second filter measuring $2 \mathrm{~mm} \times 2 \mathrm{~mm}$. The coal sample used has a total mass of 320 grams. The heat exchanger was made of a copper tube of $3 \mathrm{~mm}$ outer diameter and formed to be a helix with $45 \mathrm{~mm}$ diameter and $57 \mathrm{~mm}$ height. The tube was connected to a cooling water supply via an electric pump. The heat exchanger was maintained to flow the cooling water at $4 \mathrm{~L} /$ hour rate. The cooling water pump was activated when the temperature at the center of the reactor reached the oven temperature $(400 \mathrm{~K})$. Eight thermocouples were placed within the reactor to measure the sample temperature during oven heating. Another two thermocouples were installed in the inlet and outlet section of the heat exchanger. Later on, probe 3, located in the reactor's center, was taken into analysis in the next sections. All thermocouples were connected directly to the data logger, which recorded data at intervals of 10 seconds. 


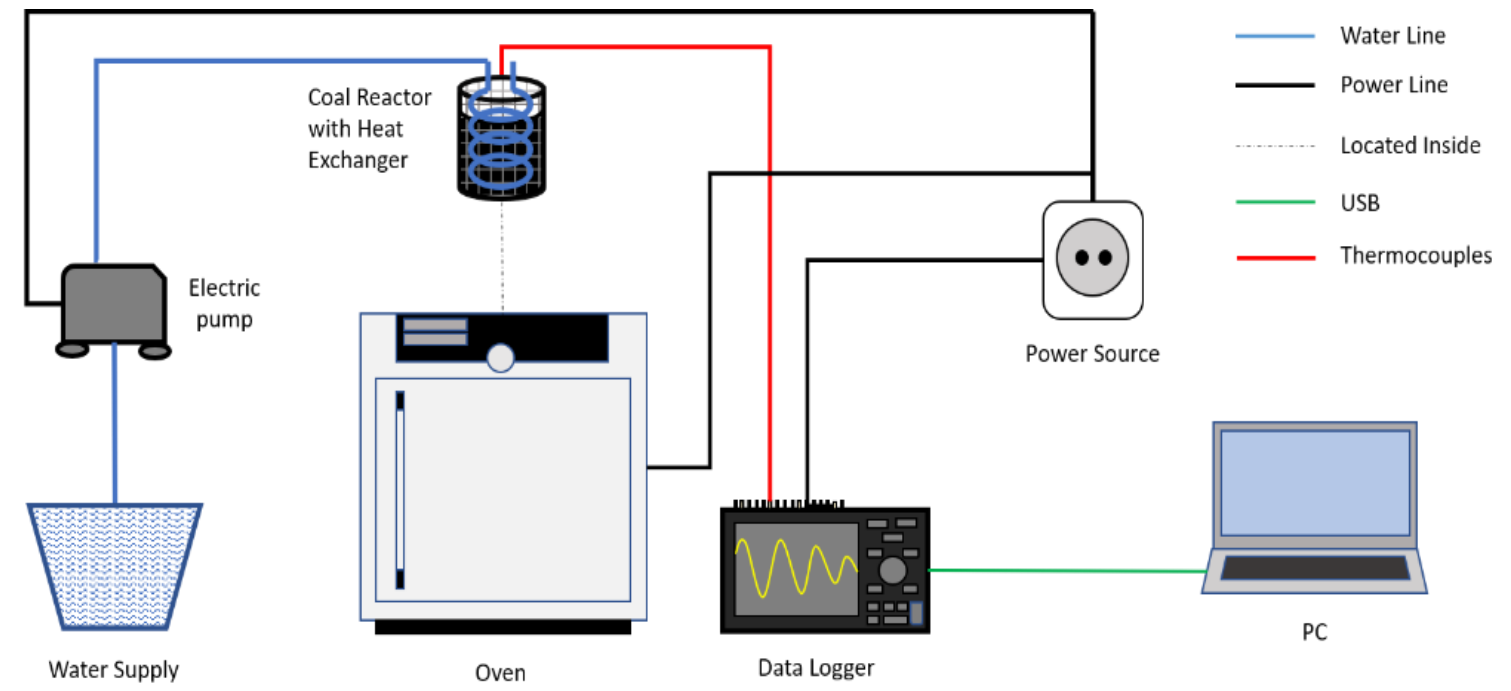

Fig. 1. Experimental Set-Up

\subsection{Simulation Model}

The laboratory experiment utilized an oven as the external source of heat to simulate the changing temperature of coal storage. Coal was assumed to be piled in a cylindrical shape inside the electric oven with $100 \mathrm{~mm}$ in diameter and $115 \mathrm{~mm}$ height. A helix acting as the heat exchanger was immersed in the middle of the coal pile, with $320 \mathrm{~K}$ water as the cooling agent. The number of coils was varied from two to seven twists, as presented in Figure 2 to simulate the variation of heat removal surface area.
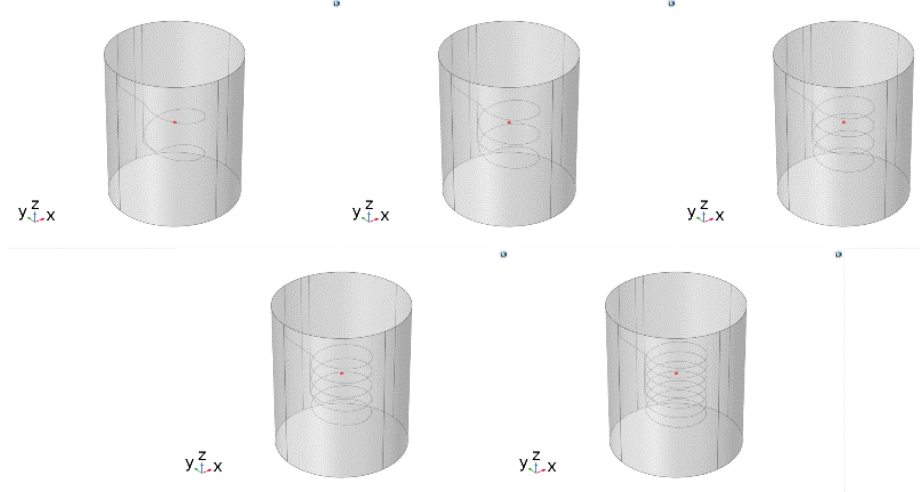

Fig. 2. Model geometry with windings variation with probe 3 (red dot) installed at the center of each reactor

The study was conducted in two steps. Firstly, the reactor is being heated as in the laboratory experiment and then activating the heat exchanger. The oven was initially at ambient temperature $(290 \mathrm{~K})$ and then heated dynamically and maintained at $400 \mathrm{~K}$. The time-dependent heat transfer within the pile domain was done using the energy balance of Eq. (1). Physical properties used in the energy balance were the mixture or practical properties based on its porous nature.

$$
\begin{aligned}
& \left(\rho C_{p}\right)_{\text {eff }} \frac{\partial T}{\partial t}+\rho C_{p} \mathrm{u} \cdot \nabla T+\nabla \cdot\left(-k_{\mathrm{eff}} \nabla T\right)=Q_{\mathrm{rx}} \\
& \left(\rho C_{p}\right)_{\mathrm{eff}}=\theta_{\mathrm{p}} \rho_{\mathrm{p}} C_{p \cdot \mathrm{p}}+\left(1-\theta_{\mathrm{p}}\right) \rho C_{p}
\end{aligned}
$$


$k_{\mathrm{eff}}=\theta_{\mathrm{p}} k_{\mathrm{p}}+\left(1-\theta_{\mathrm{p}}\right) k$

Heat transfer from the oven to the coal bed were modeled using surface-to-ambient radiation flux as shown in Eq. (4).

$-\mathrm{n} \cdot \mathrm{q}=\varepsilon \sigma\left(T_{\mathrm{oven}}^{4}-T^{4}\right)$

Coal spontaneous combustion was modeled as a first-order reaction where oxygen concentration was incorporated in the heat source equation where $R$ is a universal gas constant, and $T$ is temperature.

$Q_{\mathrm{rx}}=-\Delta H_{\mathrm{rx}} R_{\text {coal }}$

$R_{\text {coal }}=A \exp \left(-\frac{E_{a}}{R T}\right) C_{\mathrm{O}_{2}}\left(1-\theta_{p}\right)$

Secondly, for the cooling step, the water was assumed to be flowing like a steady plug flow; thus, it can be measured using Eq. (7). Water flows at the rate of $1.11 \times 10^{-6} \mathrm{~m}^{3} / \mathrm{s}$.

$$
\begin{aligned}
& Q_{\mathrm{HE}}=\dot{m} C_{p}\left(T-T_{\mathrm{H}_{2} \mathrm{O}}\right) \\
& \lim _{\partial S \rightarrow 0} \int_{\partial S} Q_{\mathrm{HE}} d S
\end{aligned}
$$

Model validation was done by using the data from the characterization experiment. The characterization experiment was done by setting the oven temperature to $400 \mathrm{~K}$ and let the reactor be heated until it experienced a rapid temperature rose, as shown in Figure 3. All constants and initial conditions used in the model can be viewed in Table 1.



Fig. 3. Model validation between experiment and simulation showed that the modeled coal reactor was reactive and underwent spontaneous combustion 


\section{Table 1}

Initial conditions values and constants used in the model

\begin{tabular}{llll}
\hline Parameter (Symbol) & Value & Unit & Reference \\
\hline Bulk density of coal $(\rho)$ & 880 & $\mathrm{~kg} / \mathrm{m}^{3}$ & {$[8]$} \\
Heat of reaction $\left(\Delta H_{r x}\right)$ & 350 & $\mathrm{~kJ} / \mathrm{mol} \mathrm{O}_{2}$ & {$[8]$} \\
Activation Energy $\left(\mathrm{E}_{\mathrm{a}}\right)$ & 95 & $\mathrm{~kJ} / \mathrm{mol}$ & {$[14]$} \\
Pre - Exponential factor $(\mathrm{A})$ & $2.88 \times 10^{6}$ & $1 / \mathrm{s}$ & {$[8]$} \\
Conductivity of coal $(k)$ & 0.1 & $\mathrm{~W} /(\mathrm{m} \mathrm{K})$ & {$[8]$} \\
Specific heat of coal $\left(C_{p \mathrm{p}}\right)$ & 1100 & $\mathrm{~J} /(\mathrm{kg} \mathrm{K})$ & {$[8]$} \\
Water flow rate $(\dot{m})$ & $1.11 \times 10^{-6}$ & $\mathrm{~m}^{3} / \mathrm{s}$ & {$[8]$} \\
\hline
\end{tabular}

\section{Results}

\subsection{Final Cooling Temperature}

The post-water pump activation phenomenon was the core of analyses. Figure 4 stated that increasing the heat exchanger's surface area means achieving a lower temperature inside the coal reactor. However, by seeing the graph's trendline, at some points, it will not have significant changes, which means adding more surface area is less impactful to its heat absorption competencies. It happened because the flowing cooling water has reached its maximum capacity to absorb the generated heat from the coal oxidation. The differences between experiment and simulation occurred due to external factors such as the uniformity of coal particle in size, which affected the heat transfer phenomenon and caused different equilibrium temperatures and time spent to reach it [15]. Both results were in agreement to show heat exchanger with seven windings could reach the lowest temperature, which means that this installment was the most optimum configuration for a coal pile with dimensional characteristics as specified for this study.

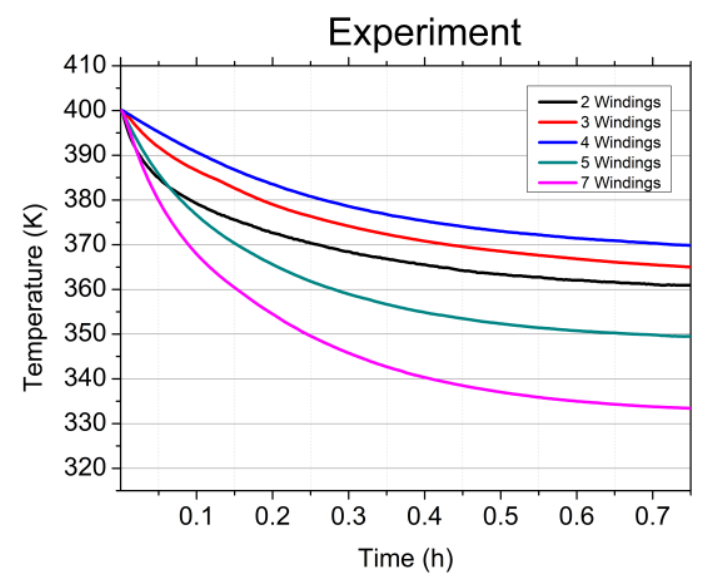

(a)

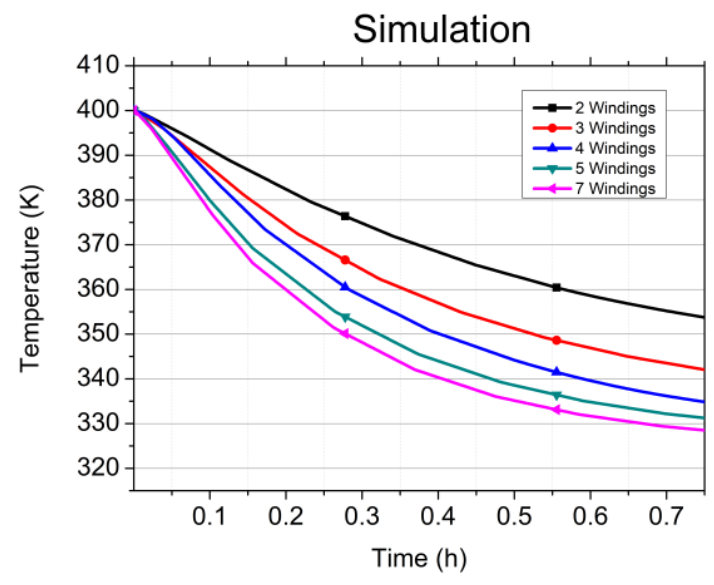

(b)

Fig. 4. Temperature profiles from probe 3 inside the coal pile;(a) experiment, (b) simulation. Both graphs were the conditions when cooling water was flown after the coal pile experience temperature rose until the oven temperature $(400 \mathrm{~K})$

\subsection{Heat Distribution}

Taking the sliced views from the two models (Figure 5), the cooling process's affected area was analyzed and showing a gradually enlarged region over time based on the temperature profile. The model with a higher number of windings could undertake a more substantial area temperature controlling than the smaller one. Comparing both models, by taking one time period as a constraint, 
the model with more windings developed the cooling range further in the $y$-axis than the smaller one.



(a)

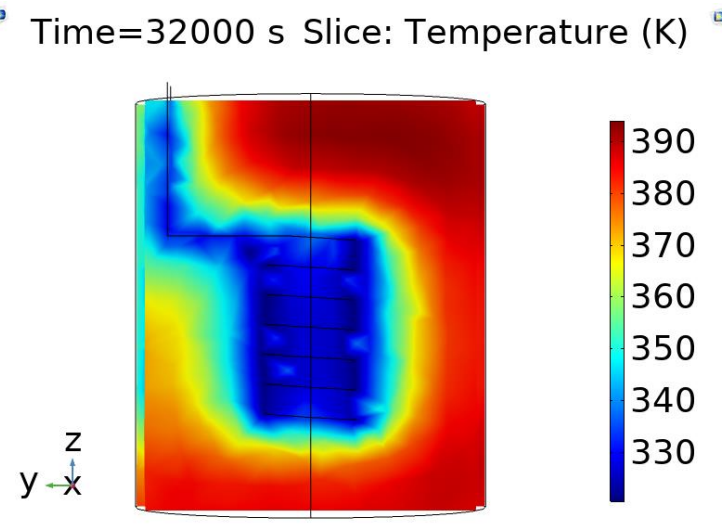

(b)

Fig. 5. Temperature distribution inside the coal reactor; (a) 2 windings instalment, (b) 7 windings instalment

\section{Conclusions}

From this study, it can be concluded that increasing the heat exchanger's surface area could result in better heat absorbing performance. However, there will be stable conditions where the heat absorbing performance tends to be steady, even if the heat exchanger surface area is enlarged. Simultaneously, the heat exchanger with more windings addressed the heated region further while the cooling process is done. It also could reach the steady-state of cooling faster than the least. Consequently, the heat exchanger design optimisation can be done by considering the number of windings and heat-absorbing performance from the heat exchanger.

\section{Acknowledgement}

The authors would like to thank the financial support provided by the Ministry of Education and Culture of the Republic of Indonesia through Penelitian Dasar Unggulan Perguruan Tinggi (PDUPT) 2020 funding scheme under Grant No. NKB-275/UN2.RST/HKP.05.00/2020 managed by the Directorate for Research and Public Services (DRPM) Universitas Indonesia.

\section{References}

[1] Song, Zeyang, Xinyan Huang, Juncheng Jiang, and Xuhai Pan. "A laboratory approach to CO2 and CO emission factors from underground coal fires." International Journal of Coal Geology 219 (2020): 103382. https://doi.org/10.1016/i.coal.2019.103382

[2] Song, Zeyang, and Claudia Kuenzer. "Coal fires in China over the last decade: a comprehensive review." International Journal of Coal Geology 133 (2014): 72-99. https://doi.org/10.1016/i.coal.2014.09.004

[3] Hu, Shengyong, Yisheng Huang, Guorui Feng, He Shao, Qi Liao, Yang Gao, and Fei Hu. "Investigation on the design of atomization device for coal dust suppression in underground roadways." Process Safety and Environmental Protection 129 (2019): 230-237. https://doi.org/10.1016/i.psep.2019.07.010

[4] Wan-xing, Ren, Kang Zeng-hui, and Wang De-ming. "Causes of Spontaneous Combustion of Coal and Its Prevention Technology in The Tunnel Fall of Ground of Extra-thick Coal Seam." Procedia Engineering 26 (2011): 717-724. https://doi.org/10.1016/i.proeng.2011.11.2228

[5] Kim, Chul Jin, and Chae Hoon Sohn. "A novel method to suppress spontaneous ignition of coal stockpiles in a coal storage yard." Fuel Processing Technology 100 (2012): 73-83. https://doi.org/10.1016/j.fuproc.2012.03.011 
[6] Liu, Yin, Hu Wen, Jun Guo, Yongfei Jin, Gaoming Wei, and Zhengwei Yang. "Coal spontaneous combustion and N2 suppression in triple goafs: A numerical simulation and experimental study." Fuel 271 (2020): 117625. https://doi.org/10.1016/i.fuel.2020.117625

[7] Mikalsen, Ragni Fjellgaard, Bjarne Christian Hagen, Anne Steen-Hansen, and Vidar Frette. "Extinguishing smoldering fires in wood pellets through cooling." 5th Magdeburg fire and explosions days (2017).

[8] Nugroho, Y. S. "Temperature Mapping on the Effectiveness of Heat Exchanger Submersion on Controlling Spontaneous Combustion of Coal Piles." (2019).

[9] Zhafira, Hanifa Khansa, Anindia Setyo Widiani, and Yulianto Sulistyo Nugroho. "Control of Spontaneous Combustion of Sub-Bituminous Coal by Means of Heat Exchanger Submersion inside the Piles." In Journal of Physics: Conference Series, vol. 1107, no. 6, p. 062004. IOP Publishing Ltd., 2018. https://doi.org/10.1088/1742-6596/1107/6/062004

[10] Wicaksono, Ricky Putro Satrio, Sofi Hesti Fathia, Inkasandra Faranisa Kolang, Achmad Riadi, Wahyu Nirbito, Yuswan Muharam, and Yulianto Sulistyo Nugroho. "Effect of the Heat Transfer Surface on Prevention of Spontaneous Combustion of Coal." Submitted tolnternational Tropical Renewable Energy (2019). https://doi.org/10.14716/ijtech.v10i6.3620

[11] Saleh, Muksin, Yuswan Muharram, and Yulianto S. Nugroho. "Modeling of the Crossing Point Temperature Phenomenon in the Low-temperature Oxidation of Coal." Int. J. Technol 1 (2017): 104-113. https://doi.org/10.14716/ijtech.v8i1.4488

[12] Rúa, Moisés Oswaldo Bustamante, Alan José Daza Aragón, and Pablo Bustamante Baena. "A study of fire propagation in coal seam with numerical simulation of heat transfer and chemical reaction rate in mining field." International Journal of Mining Science and Technology 29, no. 6 (2019): 873-879. https://doi.org/10.1016/i.ijmst.2019.09.003

[13] Li, He, Chunshan Zheng, Jiexin Lu, Li Tian, Yi Lu, Qing Ye, Wenke Luo, and Xiangnan Zhu. "Drying kinetics of coal under microwave irradiation based on a coupled electromagnetic, heat transfer and multiphase porous media model." Fuel 256 (2019): 115966. https://doi.org/10.1016/i.fuel.2019.115966

[14] Nugroho, Yulianto Sulistyo, A. C. Mclntosh, and B. M. Gibbs. "Using the crossing point method to assess the selfheating behavior of Indonesian coals." In Symposium (International) on Combustion, vol. 27, no. 2, pp. $2981-2989$. Elsevier, 1998. https://doi.org/10.1016/S0082-0784(98)80158-6

[15] Nugroho, Yulianto S., Andrew C. McIntosh, and Bernard M. Gibbs. "On the prediction of thermal runaway of coal piles of differing dimension by using a correlation between heat release and activation energy." Proceedings of the Combustion Institute 28, no. 2 (2000): 2321-2327. https://doi.org/10.1016/S0082-0784(00)80643-8 